\title{
Pandemic influenza A (H1N1) 2009: epidemiological analysis of cases in a tropical/semi-arid region of Brazil
}

\author{
Roberto da Justa Pires Neto[1], Daniele Rocha Queiroz Lemos ${ }^{[1],[2],}$ \\ Luciano Pamplona de Góes Cavalcanti ${ }^{[1],[3]}$, Alberto Novaes Ramos Junior ${ }^{[1]}$, \\ Carlos Henrique Alencar ${ }^{[1]}$, Mônica Cardoso Façanha ${ }^{[1]}$, Madalena Isabel Coelho Barroso ${ }^{[2],}$ \\ Dina Cortez Lima Feitosa Vilar ${ }^{[2]}$ and Manoel Dias da Fonseca Neto ${ }^{[2]}$
}

[1]. Departamento de Saúde Comunitária, Faculdade de Medicina, Universidade Federal do Ceará, Fortaleza, CE. [2]. Núcleo de Vigilância Epidemiológica, Secretaria da Saúde do Estado do Ceará, Fortaleza, CE. [3]. Faculdade de Medicina Christus, Fortaleza, CE.

\begin{abstract}
Introduction: The year 2009 marked the beginning of a pandemic caused by a new variant of influenza A(H1N1). After spreading through North America, the pandemic influenza virus (H1N1) 2009 spread rapidly throughout the world. The aim of this study was to describe the clinical and epidemiological characteristics of cases of pandemic influenza in a tropical/semi-arid region of Brazil. Methods: A retrospective study analyzed all suspected cases of pandemic influenza (H1N1) 2009 reported in the Ceará State through the National Information System for Notifiable Diseases during the pandemic period between 28 April, 2009 and November 25, 2010. Results: A total of 616 suspected cases were notified, $58(9.4 \%)$ in the containment phase and $558(90.6 \%)$ in the mitigation phase. Most cases were of affected young people resident in the City of Fortaleza, the largest urban center in the State of Ceará. The most frequent symptoms presented by the cases with confirmed infection were fever, cough, myalgia, arthralgia, and nasal congestion. Mortality rate was $0.0009 / 1,000$ inhabitants and lethality was $5.6 \%$. Deaths were observed only in the mitigation phase. Mortality rates were similar for both sexes but were higher in the age group under 5 years. Conclusions: The study suggests that the influenza A $(\mathrm{H} 1 \mathrm{~N} 1)$ pandemic in this tropical/semi-arid region had a lower magnitude when compared to states in the Southern and Southeastern regions of Brazil.
\end{abstract}

Keywords: Pandemic influenza (H1N1) 2009. Tropical/semi-arid region. Epidemiology. Clinical characteristics.

\section{INTRODUCTION}

The year 2009 marked the beginning of a pandemic caused by a new variant of influenza A (H1N1). The occurrence began in March with the registration of a higher than expected increase in cases of a flu-like illness and the concomitant occurrence of atypical cases of pneumonia in Mexico ${ }^{1}$. In early April 2009, the Centers for Disease Control and Prevention (CDC/Atlanta / USA) identified the etiological agent, currently called the pandemic influenza virus (H1N1) 2009, and reported this finding to the World Health Organization (WHO) in accordance with the International Health Regulations 2005 (RSI 2005) $)^{2}$. On April 25 th 2009 , the WHO declared a Public Health Emergency of International Concern (PHEIC).

Address to: Dr. Roberto da Justa Pires Neto. Depto. de Saúde Comunitária/ FM/UFC. Rua Prof. Costa Mendes 1.608, $5^{\circ}$ andar, Rodolfo Teófilo, 60430-140 Fortaleza, CE, Brasil.

Phone: 5585 3366-8044; 5585 3366-8045

e-mail: robertojusta@ufc.br

Received in 07 October 2012

Accepted in 15 February 2013
After spreading through North America in the first half of 2009, the virus spread rapidly throughout the world, and consequently, the declaration of a pandemic was the scientific confirmation that an emerging virus was spreading globally ${ }^{3}$. In March 2010, almost all the countries in the world reported cases confirmed by laboratory tests, and more than 17,700 deaths among those cases were reported to the $\mathrm{WHO}^{4}$. On August $10^{\text {th }} 2010$, after the post-peak pandemic period, the WHO declared the end of the pandemic and the start of the post-pandemic period 5 .

In Brazil, the first case was confirmed on May $7^{\text {th }} 2009$. By the declaration of the end of the pandemic in the country, 105,227 cases had been reported with 54,171 confirmations and 2,232 deaths ${ }^{6}$. In Ceará, many cases were reported, with complications and deaths. The aim of this study is to describe the clinical and epidemiological characteristics of the cases of pandemic influenza in the State of Ceará, Northeast Brazil, in 2009/2010.

\section{METHODS}

This is a descriptive and retrospective study that analyzes all suspected cases of pandemic influenza (H1N1) reported in 2009 in Ceará, through the Information System for Notifiable 
Diseases (SINANWeb) during the influenza pandemic of a new subtype, between $28^{\text {th }}$ April 2009 and November $25^{\text {th }} 2010$.

Following the World Health Organization guidelines ${ }^{7,8}$, the definition of a suspect case of the new subtype of pandemic influenza varied during the period of the pandemic. In Brazil, the pandemic was divided into two distinct epidemiological and operational phases: phase $1-$ containment and phase $2-$ mitigation $^{8}$. The terminology used in case definitions classified respiratory infections into influenza pandemic (H1N1) 2009 influenza-like illness and severe acute respiratory infection (SARI).

The containment phase corresponded with the period in which the virus was spreading around the world and cases were related to international travel or through contact with sick people who had made international journeys ${ }^{4}$. In Ceará, this phase extended from the epidemiological week (EW) 16 (19 ${ }^{\text {th }}$ to $25^{\text {th }}$ April, 2009), when the first suspected cases were identified, until the period of the EW 28 (12 $2^{\text {th }}$ to $18^{\text {th }}$ July, 2009), a period when the sustained transmission of pandemic influenza was declared across the country. The mitigation phase included the period from the EW $29\left(19^{\text {th }}\right.$ to $25^{\text {th }}$ July 2009) until the declared end of the pandemic ${ }^{9}$. Confirmed cases were defined as those with positive results for real-time PCR or having an epidemiologic link. The Windows application Epi-Info version 3.5.1 was used for data analysis.

\section{Ethical considerations}

This study followed the ethical principles set out in Resolution 196/96 and was approved by the Ethics Committee of Hospital São José de Doenças Infecciosas.

\section{RESULTS}

In Ceará, in the pandemic period (April 19, 2009 to November 18, 2010), 616 suspected cases were reported, of which $58(9.4 \%)$ were during the containment phase and 558 $(90.6 \%)$ in the mitigation phase.

In the containment phase, $45(77.6 \%)$ cases of influenza-like illness and 13 (22.4\%) cases of SARI were reported. The first cases were reported in EW 16/2009 and the first case was confirmed in the EW 24/2009. In the mitigation phase $254(45.5 \%)$ cases of flu-like illness and $304(54.5 \%)$ cases of SARI were reported. Influenza A (H1N1) was confirmed in $143(23.2 \%)$ patients. The number of confirmed cases of influenza A(H1N1) infections differed according to each period of analysis. In the containment phase, $27(46.6 \%)$ of the 58 reported cases confirmed influenza A (H1N1) infection. In the mitigation phase, among 558 cases, only $116(20.8 \%)$ were confirmed with influenza A (H1N1) infection (Table 1).

In EW 4/2010, the highest frequency of confirmed cases of SARI was present, with an incidence of 0.03 cases per 100,000 inhabitants. From EW 12/2010, there was continuous reduction in the incidence of confirmed cases with just one case confirmed in EW 23/2010 (Figure 1).

In the containment phase, the municipality with the highest frequency of suspected cases was Fortaleza, the state capital, with $95.9 \%$ (47/49) of the reported cases. The same occurred in the mitigation phase, with $48.5 \%$ (275/567) of the reported suspected cases being from Fortaleza. The municipality of residence of $85.2 \%(23 / 27)$ of the confirmed cases was

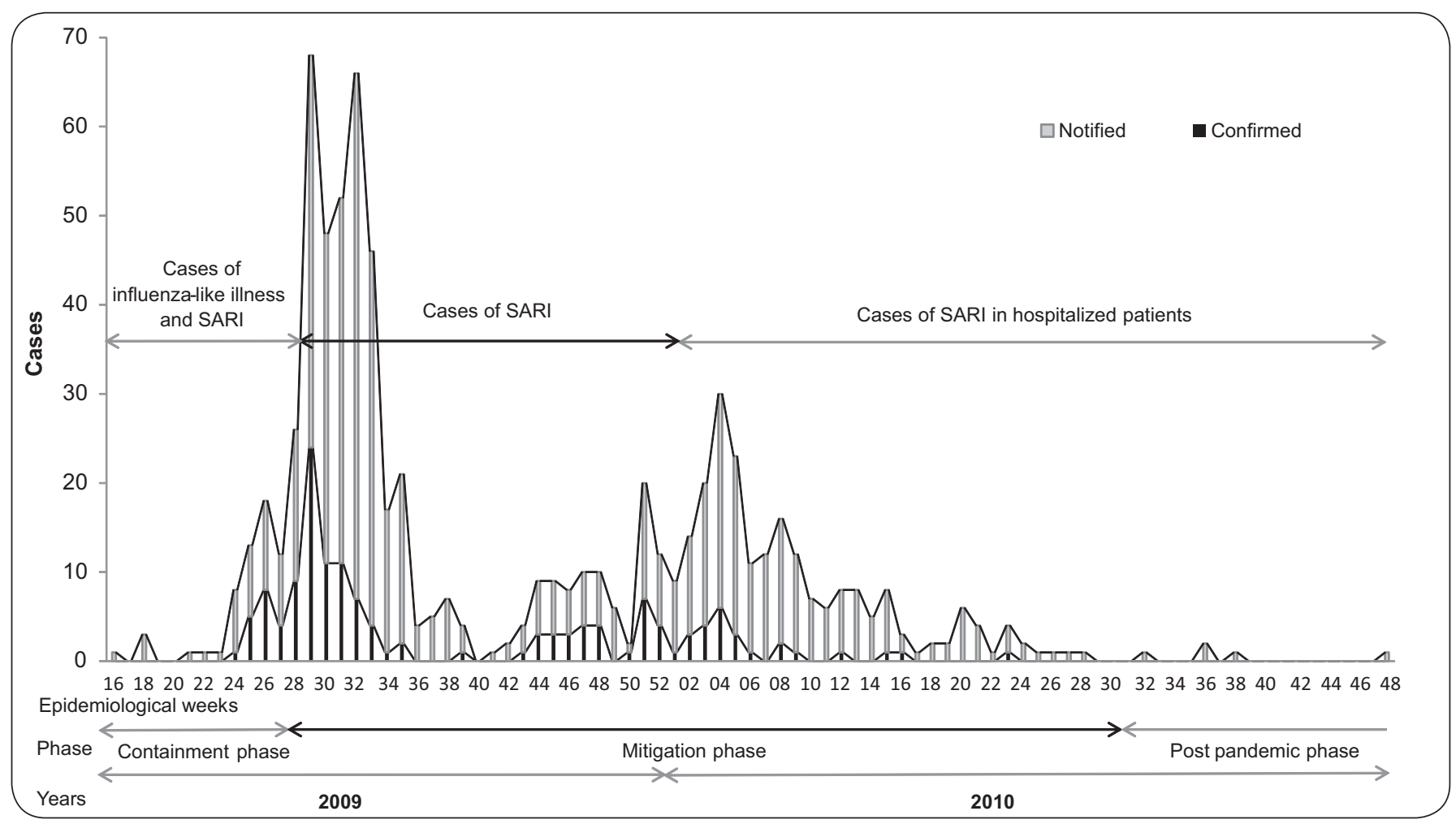

FIGURE 1 - Notified and confirmed cases of pandemic influenza A (H1N1) 2009 by epidemiological week, phase and year, State of Ceará, Brazil, $2009-2010$. 
TABLE 1 - Cases of pandemic influenza A (H1N1) 2009 by gender and age, containment and mitigation phases, State of Ceará, Brazil, 2009-2010

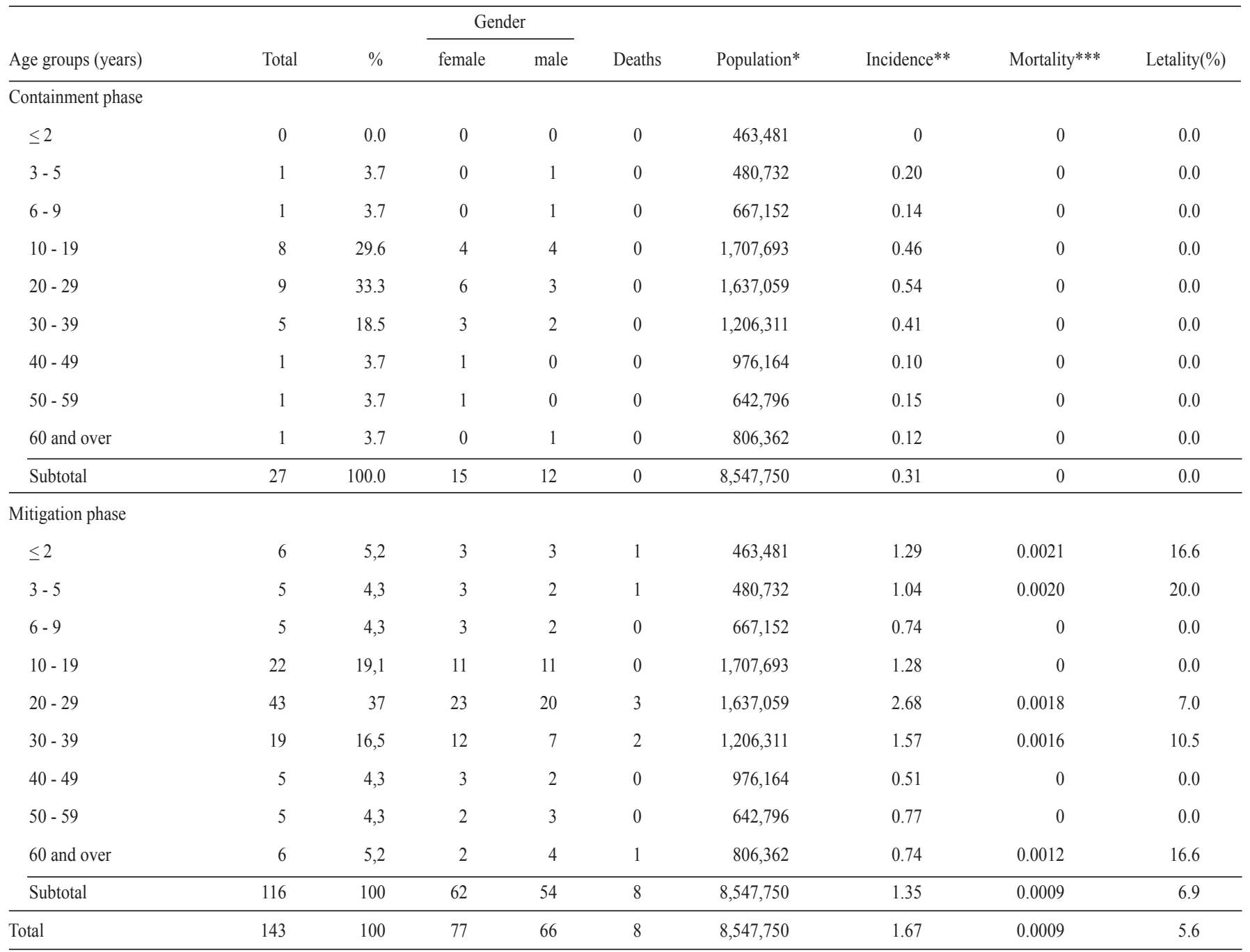

*Source: Population of Ceará State according to Departamento de Informática do Sistema Único de Saúde (DATASUS), 2011.**Number of cases/100,000 inhabitants. ***Number of deaths/1,000 inhabitants.

also Fortaleza. The other 11.1\% (3/27) lived in other states (Rio de Janeiro and São Paulo) and 3.7\% (1/27) were from Quixadá$\mathrm{CE}$. In the mitigation phase, the municipality of residence in $88.8 \%(103 / 116)$ of the confirmed cases was Fortaleza-CE and $5.2 \%$ (6/116) lived in other States (Rio de Janeiro and São Paulo).

In the containment phase, the confirmation of cases through laboratory tests occurred in $96.3 \%$ (26/27) of the cases and $3.7 \%(1 / 27)$ were diagnosed by an epidemiologic link. Among the 13 SARI patients, $53.8 \%$ (7/13) were hospitalized, $84.6 \%$ $(11 / 13)$ were tested with real-time PCR and $46.2 \%(6 / 13)$ were confirmed with Influenza A (H1N1). Of the confirmed cases, $7.4 \%(2 / 27)$ were hospitalized.

Confirmation of cases by laboratory testing in the mitigation phase occurred in $88.8 \%(103 / 116)$ of the cases and $11.2 \%$ $(13 / 116)$ were diagnosed by an epidemiologic link. Among the cases reported at this stage, $30.5 \%$ (170/558) were hospitalized, and $44.1 \%(75 / 170)$ were hospitalized in state referral units. Of the total confirmed, $21.6 \%(25 / 116)$ of the patients were hospitalized. However, among those affected by the disease and those who had developed SARI, 41.4\% (24/58) were hospitalized, $86.2 \%(50 / 58)$ were tested with real-time PCR and all were confirmed for influenza A (H1N1).

The epidemiologic characteristics of the patients affected according to the pandemic phase are presented in Table 2. In the containment phase the majority (87.8\%) of those affected by pandemic influenza (H1N1) 2009 had high educational level (12 or more years of study). Among those affected in the mitigation phase, the level of education was lower, with $50 \%$ under 12 years of schooling. The most frequent symptoms observed in the patients according to gender are shown in Figure 2. Of the total confirmed cases in the containment phase, 33.3\% (9/27) had an associated chronic comorbidity, such as chronic heart disease, smoking, and others. Whereas in the mitigation phase, of the total confirmed cases, $24.1 \%$ (28/116) of the patients had some type of chronic health condition.

Deaths were only observed in the mitigation phase. Up to EW $23 / 2010$, there were 30 suspicious deaths. Only 8 deaths were confirmed to be secondary to pandemic influenza (confirmed deaths). Mortality rates were similar for both sexes but were higher in the age group under 5 years (Table 1). Among 
TABLE 2 - Epidemiological variables in patients affected by the pandemic influenza A (H1N1) 2009, containment and mitigation phases, State of Ceará, Brazil, 2009-2010

\begin{tabular}{lrrrrr}
\hline & \multicolumn{2}{c}{ Containment phase } & & \multicolumn{2}{c}{ Mitigation phase } \\
\cline { 2 - 3 } \cline { 5 - 6 } Variables & $\mathrm{n}$ & $\%$ & & $\mathrm{n}$ & $\%$ \\
\hline $\begin{array}{l}\text { Gender } \\
\text { female }\end{array}$ & $15 / 27$ & 55.5 & & $62 / 116$ & 53.4 \\
\hline $\begin{array}{l}\text { Reproduction* } \\
\text { Fertile age }\end{array}$ & $14 / 15$ & 93.3 & & $48 / 62$ & 77.4 \\
$\quad$ Pregnant & - & - & & $14 / 62$ & 22.6 \\
\hline Racial & $21 / 27$ & 77.7 & & $48 / 109$ & 44.0 \\
$\quad$ white & $3 / 27$ & 11.1 & & $52 / 109$ & 47.7 \\
multiracial & - & - & & $3 / 109$ & 2.8 \\
$\quad$ black & & & & & \\
\hline
\end{tabular}

\begin{tabular}{lrrrr}
\hline $\begin{array}{l}\text { Residence area } \\
\text { urban }\end{array}$ & $27 / 27$ & 100 & $105 / 106$ & 99.1 \\
rural & - & - & $1 / 106$ & 0.9 \\
\hline Comorbidity & $9 / 27$ & 33.3 & $28 / 116$ & 24.1 \\
\hline Old age** & $1 / 27$ & 3.7 & $6 / 116$ & 5.2 \\
\hline Age (years) & & & & \\
mean & $26(5-63)^{* * *}$ & $27(9-79)^{* * *}$ \\
median & 23 & \multicolumn{2}{c}{24} \\
\hline
\end{tabular}

*Aspects related to human reproduction; $* *$ Old age $\geq 60$ years; *** Minimum and maximum values.

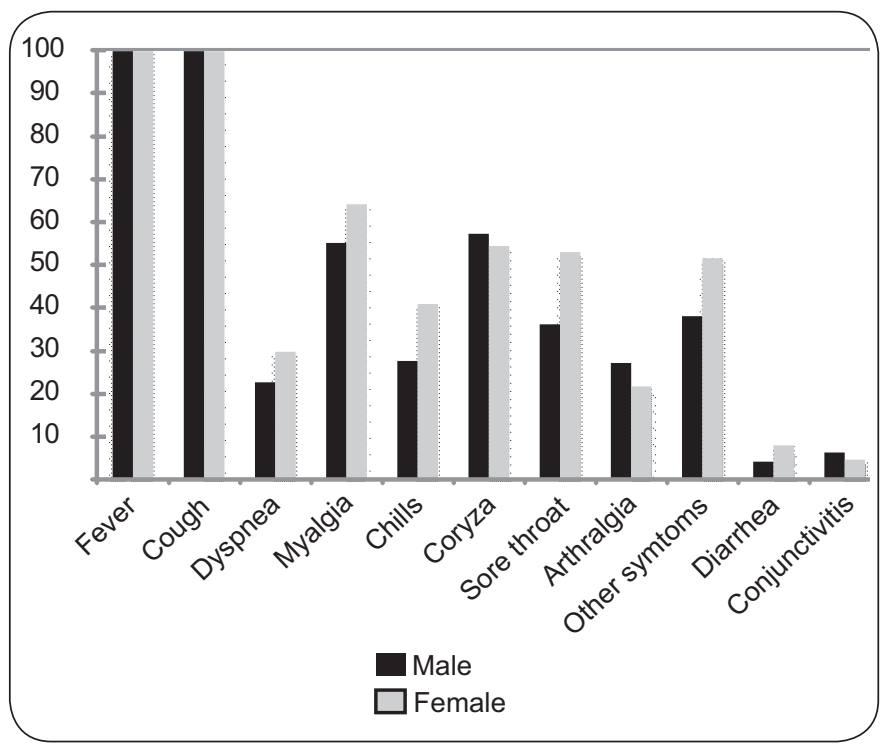

FIGURE 2 - Symptoms reported by patients with confirmed cases of pandemic influenza A (H1N1), State of Ceará, Brazil, 2009-2010.

the confirmed deaths $(8 / 30)$, the median age was 27 years $(<1$ year-62 years) and females were more affected (5/8). Of the affected females, all were of childbearing age (10-49 years) and $60 \%(3 / 5)$ were pregnant. Of the total number of confirmed deaths, $62.5 \%(5 / 8)$ had at least one risk factor for severity, with the pregnant women accounting for $37.5 \%$. Deaths occurred in EWs $1,3,4,6,8$, and 25 of 2010 . The mortality rate was 0.0009 deaths $/ 1,000$ inhabitants and the lethality was $5.6 \%$.

\section{DISCUSSION}

In March 1918, a severe influenza epidemic spread across the world, beginning simultaneously in the U.S. and Europe and killing about 40 million people, making it the most catastrophic medical event in human history ${ }^{10}$. Since then, the monitoring systems of the influenza virus have detected changes in the epidemic strains of influenza A viruses every 1-2 years. During these 92 years, two pandemics of influenza A viruses were detected in 1957 (H2N2) and 1968 (H3N2), although with much lower mortality rates $^{11-13}$. In 2009, the same surveillance system identified a new virus $\mathrm{A}$, and because of an increase in hospitalizations for severe respiratory illness, Mexico declared the outbreak of an influenza pandemic alerted by the health authorities ${ }^{14}$.

This study provides important clinical and epidemiological information on pandemic influenza H1N1 2009 in a state in northeastern Brazil, an area close to the equator, with a semiarid climate and without the occurrence of the four well-defined seasons. In this scenario, the pandemic was characterized by affecting young people, supporting global and national data showing a higher frequency in patients younger than 50 years ${ }^{15-17}$, in contrast to seasonal flu that occurs with more severity among people over $65^{4}$. In Brazil, in 2009, 63.5\% and $62.1 \%$ of the confirmed cases in the containment and mitigation phases, respectively, were patients younger than 30 years 9 . The average age in this analysis was similar to that found in Canada and some European countries ${ }^{18}$. In the United States, this proportion was $84.1 \%$ of whom $60 \%$ were 18 years or below, while in Mexico the rate was $78.7 \%{ }^{18}$. There was no significant difference in the incidence of the pandemic between genders as in the data presented in other studies ${ }^{17,19,20}$.

In the containment phase, the vast majority of the reported cases in this series occurred in Caucasians and/or those with higher education. In the mitigation phase, cases were mainly of mixed race individuals who had completed high school. One explanation for this finding lies in the fact that at the beginning of the pandemic virus transmission took place mainly among individuals with higher purchasing power and a greater possibility of coming into contact with the virus in the regions abroad where the virus had been declared as present, or with people who had direct contact with these travelers. In a study evaluating cases in the State of Paraná, in the Southern region of the country, the incidence of influenza A(H1N1) in 2009 in a particular ethnic group was lower ${ }^{17}$.

In terms of geographical distribution, almost all the cases of influenza A H1N1 pandemic in the State of Ceará were of individuals living in the capital city of Fortaleza. The Ministry of Health reported that 26 state capitals were responsible for $60.7 \%$ of the notifications in the mitigation phase, while in the containment phase this number was $48.4 \%{ }^{6}$. These data confirm that the capital cities were the main notifiers and suggest that influenza cases were not spreading to the interior, although a possible explanation for the lower notification rates among small cities is subnotification.

In terms of clinical distribution, the symptoms presented by the cases with confirmed pandemic H1N1 infection are similar to those found in other studies ${ }^{2,3,19-21}$, with the occurrence of 
fever, cough, myalgia, arthralgia, and nasal discharge. As to the evolution of cases during the mitigation phase, the ratio of hospitalized subjects was about three times greater than in the containment phase. The authors suggest that this finding was because of the changes in case definition issued by the Ministry of Health in EW 29 of $2010^{8}$. In a study performed at the Hospital and Clinics of the State University of Campinas (HC-UNICAMP), Campinas, São Paulo, Brazil, including all patients attended from April $28^{\text {th }}$ to December $31^{\text {st }}, 2009$, whose case were identified as mandatory notification for influenza A (H1N1), 48.9\% were hospitalized ${ }^{21}$. In the United States, nearly $10 \%$ of the confirmed cases of influenza A (H1N1) were hospitalized, and in Mexico 20\% of the patients hospitalized for pneumonia in a hospital for respiratory diseases had confirmed the existence of the new virus ${ }^{22}$. These two characteristics are different from the normal behavior of seasonal flu and are similar to that observed in the influenza pandemic of 1918 when there was a greater number of cases with severe respiratory disease in young individuals from different countries ${ }^{23,24}$. Hospitalization rates during the 2009 pandemic varied widely according to the city. Worldwide, hospitalization rates were higher for children under 5 years, especially those under the age of one year, and lower for people aged 65 or older ${ }^{19,25}$.

Approximately $50 \%$ of those patients infected with the virus (H1N1) in 2009 who were hospitalized or died did not present any comorbidity ${ }^{19,26}$. In the containment phase, the proportion was much higher, reaching two thirds, while in the mitigation phase the non-reference of comorbidities was close to the level found worldwide; about one quarter. Pregnant women (especially, the second or third trimester), puerperal mothers, and patients with immunosuppression or neurological diseases were also represented among those who evolved with greater severity ${ }^{19,27-29}$. Jamieson et al. suggest that there is a particularly increased risk of death among those women infected during the third trimester ${ }^{30}$.

Mortality from influenza in the pandemic period was $0.0009 / 1,000$ inhabitants, according to the estimated population for Ceará by the Brazilian Institute for Geography and Statistics - $\mathrm{IBGE}^{31}$. This is similar to the mortality in the Northeast States of Sergipe, Paraiba, and Piauí, and is lower than the rate for Brazil $(0.0044 / 1,000 \text { inhabitants })^{6}$ and the States in the Southern and Southeastern regions, such as Paraná $(0.0179 / 1,000$ inhabitants), Rio Grande do Sul (0.0136/1,000 inhabitants), and Rio de Janeiro (0.0074/1,000 inhabitants) $)^{2}$. In Campinas, São Paulo, a study performed at the Hospital and Clinics of the University of Campinas (HC-UNICAMP), influenza A(H1N1) was responsible for $8(6.9 \%)$ deaths among 115 cases in adults and for $2(8.3 \%)$ deaths in 24 cases in children ${ }^{21}$.

The authors recognize that this study has limitations. Results are based on secondary data and subnotification may have occurred since influenza presents itself with a large spectrum of clinical manifestations, including many subclinical cases. However the data analysis provides in-depth knowledge about pandemic influenza (H1N1) 2009 in the State of Ceará. The study suggests that the influenza A (H1N1) pandemic in this region of Brazil in 2009 and 2010 had a lower magnitude when compared to other states in other regions of the country. Owing to the difficulty of access to information (unavailable in the reporting forms) and the epidemiological research, in-depth studies including other risk groups and risk factors for the worsening of the disease in our population should be developed.

\section{CONFLICT OF INTEREST}

The authors declare that there is no conflict of interest.

\section{REFERENCES}

1. Center for Disease Control and Prevention. Outbreak of Swine-Origin Influenza A (H1N1) Virus Infection - Mexico. MMWR 2009; 58:467-470.

2. Center for Disease Control and Prevention. Swine Influenza A (H1N1) Infection in Two Children - Southern California. MMWR 2009; 58:400-402.

3. David R. Hillyard. Novel swine-origin influenza A (H1N1) virus investigation team. N Engl J Med 2009; 360:2605-2615.

4. Bautista E, Chotpitayasunondh T, Gao Z, Harper S, Shaw M, Uyeki T, et al. Clinical aspects of pandemic 2009 influenza A (H1N1) virus infection. N Engl J Med 2010; 362:1708-1719.

5. World Health Organization. H1N1 in post-pandemic period. Retrieved October; 2010.

6. Ministério da Saúde. Departamento de Informática do Sistema Único de Saúde (DATASUS). Informações de Saúde. Sistema de Informação de Agravos de Notificação (SINAN) [Internet]. [Cited 2011 July 1]. Available from: http:// dtr2004.saude.gov.br/sinanweb/tabnet/dh?sinannet/influenza/bases/influbrnet.def.

7. Chan M. World now at the start of 2009 influenza pandemic. World Health Organization; 2009.

8. Ministério da Saúde. Protocolo de Vigilância Epidemiológica da Influenza Pandêmica (H1N1) 2009 - Notificação, Investigação e Monitoramento [Internet]. $1^{\text {st }}$ ed. 2010; [Cited 2011 July 1] Available from: http://portal.saude.gov.br/portal/ arquivos/pdf/protocolo_ve_influenza_2010.pdf.

9. Ministério da Saúde. Influenza Pandêmica (H1N1) 2009 - Análise da situação epidemiológica e da resposta no ano de 2009. Boletim Epidemiológico Eletrônico [Internet]. 2010 [Cited March 2010]; 10:[21p.]. Available from http://portal. saude.gov.br/portal/arquivos/pdf/ano10_n01_influenza_pandh1n1_br.pdf.:

10. World Health Organization. Avian influenza: assessing the pandemic threat: World Health Organization; 2005.

11. Kamps BS, Hoffmann C, Preiser W. Influenza report 2006 Flying Publisher. [Internet]. [Cited 2011 July 1]. Available from: www.influenzareport.com/

12. Morens DM, Taubenberger JK, Fauci AS. The persistent legacy of the 1918 influenza virus. N Engl J Med 2009; 361:225-229.

13. Zimmer SM, Burke DS. Historical perspective-emergence of influenza A(H1N1) viruses. N Engl J Med 2009; 361:279-285.

14. Real-Time R. Emergence of a novel swine-origin influenza A (H1N1) virus in humans. N Engl J Med 2009; 360:2605-2615.

15. Enserink M. Swine Flu names evolving faster than swine flu itself. Science. 2009; 324:871.

16. Hui DS, Lee N, Chan PKS. Clinical management of pandemic 2009 influenza A (H1N1) infection. Chest 2010; 137:916.

17. Lenzi L, Wiens A, Grochocki MHC, Pontarolo R. Study of the relationship between socio-demographic characteristics and new influenza A (H1N1). Braz J Infect Dis 2011; 15:457-461.

18. Fajardo-Dolci GE, Hernández-Torres F, Santacruz-Varela J, Rodríguez-Suárez J, Lamy P, Arboleya-Casanova H, et al. Perfil epidemiológico de la mortalidad por influenza humana A (H1N1) en México. Salud Publica Mex 2009; 51:361-371.

19. Louie JK, Acosta M, Winter K, Jean C, Gavali S, Schechter R, et al. Factors associated with death or hospitalization due to pandemic 2009 influenza A (H1N1) infection in California. JAMA 2009; 302:1896.

20. Cugini DM, Silva FPA, Éttori H, Krumenauer MZ, Moreira ME, Paulucci RS. Epidemiologic profile of cases of influenza A H1N1 in Taubaté-SP-Brazil. BEPA Boletim Epidemiológico Paulista (Online) 2010; 7:17-25. 
21. Moretti ML, Sinkoc V, Cardoso LGO, Camargo GJ, Bachur LF, Hofling CC, et al. Lessons from the epidemiological surveillance program, during the influenza A (H1N1) virus epidemic, in a reference university hospital of southeastern Brazil. Rev Soc Bras Med Trop 2011; 44:405-411.

22. Perez-Padilla R, Rosa-Zamboni D, Ponce de Leon S, Hernandez M, QuiñonesFalconi F, Bautista E, et al. Pneumonia and respiratory failure from swine-origin influenza A (H1N1) in Mexico. N Engl J Med 2009; 361:680-689.

23. Karlas A, Machuy N, Shin Y, Pleissner KP, Artarini A, Heuer D, et al. Genomewide RNAi screen identifies human host factors crucial for influenza virus replication. Nature 2010; 463:818-822.

24. König R, Stertz S, Zhou Y, Inoue A, Hoffmann HH, Bhattacharyya S, et al. Human host factors required for influenza virus replication. Nature 2009; 463:813-817.

25. Presanis AM, Angelis D, Hagy A, Reed C, Riley S, Cooper BS, et al. The severity of pandemic H1N1 influenza in the United States, from April to July 2009: a Bayesian analysis. PLoS Med 2009; 6:e1000207.

26. Libster R, Bugna J, Coviello S, Hijano DR, Dunaiewsky M, Reynoso N, et al. Pediatric hospitalizations associated with 2009 pandemic influenza A (H1N1) in Argentina. N Engl J Med 2010; 362:45-55.
27. Mashonganyika C, McKee H, Board J, Davies A, Vallance S, Hatch F, et al. Critical care services and $2009 \mathrm{H} 1 \mathrm{~N} 1$ influenza in Australia and New Zealand. N Engl J Med 2009; 361:1925-1934.

28. Jain S, Kamimoto L, Bramley AM, Schmitz AM, Benoit SR, Louie J, et al Hospitalized patients with 2009 H1N1 influenza in the United States, April-June 2009. N Engl J Med 2009; 361:1935-1944.

29. Louie JK, Acosta M, Jamieson DJ, Honein MA. Severe 2009 H1N1 influenza in pregnant and postpartum women in California. N Engl J Med 2010; 362:27-35.

30. Jamieson DJ, Honein MA, Rasmussen SA, Williams JL, Swerdlow DL, Biggerstaff MS, et al. H1N1 2009 influenza virus infection during pregnancy in the USA. Lancet 2009; 374:451-458.

31. Instituto Brasileiro de Geografia e Estatística (IBGE). Estimativas das populações residentes, em $1^{\circ}$ de julho de 2009 , segundo municípios. Brasília: IBGE: 2011. 